\title{
A View Of Cloud Computing
}

\author{
Juhnyoung Lee \\ Research Staff Member and Manager \\ IBM T. J. Watson Research Center \\ jyl@us.ibm.com \\ Received and accepted 19 November 2012
}

\begin{abstract}
Today's IT infrastructure is under tremendous pressure and is finding it difficult to keep up. In distributed computing environments, up to 85 percent of computing capacity sits idle. 66 percent of every dollar on IT is spent on maintaining current IT infrastructures versus adding new capabilities. In history, operations have industrialized to become smarter. Cloud Computing is positioned to industrialize the IT delivery of the future. It is a natural evolution of the widespread adoption of multiple technical advances in the distributed computing area including virtualization, grid computing, autonomic computing, utility computing and software-as-a-service. It provides a new paradigm for consumption and delivery of IT based services - It provides an enhanced user experience with a self-service user interface for IT management. It abstracts the technical details from end-users so that they no longer need expertise in, or control over, the technology infrastructure "in the cloud" that supports them. It provides flexible pricing based on pay per usage. It enables flexible delivery and sourcing models including private, public and hybrid clouds. Finally, it provides automated provisioning and elastic scaling of IT infrastructure. This paper presents several views on different perspectives of Cloud Computing, including technical advancement, IT delivery and deployment modes, and economics.
\end{abstract}

Keywords: Cloud, cloud computing, infrastructure, services

\section{Introduction}

As the planet gets smarter, the information explosion and rapid change create new challenges. For example, digital data is projected to grow tenfold from 2007 to 2011. Global Internet traffic volume is expected to reach 500 TB by 2013. There will be more than 1 trillion devices connected to the Internet by 2011. All of this data has the potential to provide enterprise with valuable insights for running their businesses more effectively and efficiently. Yet today's IT infrastructure is under tremendous pressure and is finding it difficult to keep up. In distributed computing environments, up to 85 percent of computing capacity sits idle. 66 percent of every dollar on IT is spent on maintaining current IT infrastructures versus adding new capabilities.

In history, operations have industrialized to become smarter. For example, telecommunication companies automate traffic through switches to assure services and lower cost. Manufacturers use robotics to improve quality and lower cost. Local calls were made through human "operators" well into the 1950s. In many parts of the country you could only make long distance calls through an operator well into the 1970s. Automation was required in order to be able to keep up with increasing call volumes. The standardization of the Ford Company's assembly line was later improved with the Toyota Production System and the implementation of new technologies, e.g. robotics. To be able to deliver the service provided by ATMs, tremendous breakthroughs in standardization were required - to enable to conduct transactions from any machine, without regard to whether you have an account with the owner of the machine.

In a similar way to address issues with the service efficiency, quality and costs, IT also needs to become smart about delivering services. The growing complexity of IT systems and soon a trillion connected things demand that sprawling processes become 
standardized services that are efficient, secure and easy to access. A service management system will provide visibility, control and automation across IT and business services to ensure consistent delivery. Cloud Computing describes a new consumption and delivery model for IT services. Its user experience and business model will provide standardized offerings rapidly provisioned and flexibly priced. Its infrastructure management and services delivery method will provide virtualized resources managed as a single large resource, and deliver services with elastic scaling. Similar to Banking ATMs and Retail Point of Sale, Cloud will be driven by self-service, simplification, standardization, economies of scale, and technology advancement.

\section{A Technical View}

Cloud computing is a natural evolution of the widespread adoption of multiple technical advances in distributed computing including virtualization, grid computing, autonomic computing, utility computing and software-as-a-service as shown in Figure 1. Virtualization [2] is an overall trend in enterprise IT that centralizes administrative tasks while improving scalability and workload by combining autonomic computing in which the IT environment will be able to manage itself based on perceived activity, and utility computing in which computer processing power is seen as a utility that clients can pay for only as needed. A precursor to this trend was grid computing in which a "super virtual computer" is composed of many networked loosely coupled computers acting together to perform very large tasks and/or dealing with sudden peaks in demand.

Utility computing is the packaging of computing resources, such as computation, storage and software, as a metered service similar to a traditional public utility (such as electricity, water, natural gas, or telephone network). This model has the advantage of a low or no initial cost to acquire computer resources; instead, computational resources are essentially rented - turning what was previously a need to purchase products (hardware, software and network bandwidth) into a service. This repackaging of computing services became the foundation of the shift to "On Demand" computing. Software as a Service and Cloud Computing further propagated the idea of computing, application and network as a service.
Software as aSservice, SaaS, is a software delivery model in which software and its associated data are hosted centrally, typically in the Internet cloud, and are typically accessed by users using a thin client, normally using a Web browser over the Internet. A characteristic of SaaS is its multi-tenant architecture which enables that a single version of software on a single set of infrastructure (hardware, operating system and network) can be shared by multiple users ("tenants") with proper isolation among themselves. To support scalability, the software may be installed on multiple machines. This configuration is contrasted with the traditional software, where multiple physical copies of the software are installed across the various customer sites. Driven by the multi-tenancy architecture, SaaS applications tend not to support individual customization that alters the source code of the application, its database schema or its GUI. Instead, multi-tenant applications are designed to support application configuration with a set of parameters that affect its functionality and look-andfeel. The application can be customized to the degree it was designed for based on a set of predefined configuration options. In addition, while SaaS applications do not access a company's internal systems, they predominantly offer integration protocols and application programming interfaces (APIs) that operate over a wide area network protocols such as HTTP, REST, SOAP and JSON.

Software as a service is an integral part of the service management system for Cloud Computing that will address the issues of efficiency, quality and costs of the traditional IT delivery model and provide visibility, control and automation across IT and business services to ensure consistent delivery. Along with SaaS, the service management system for Cloud Computing offers cloud infrastructure services, also known as Infrastructure as a Service, IaaS, which deliver computer infrastructure - typically a platform virtualization environment - as a service. The notion indicates that clients can access infrastructure resources as a fully outsourced service without purchasing servers, software, data-center space or network equipment. Suppliers typically bill such services on a utility computing basis, that is, the amount of resources consumed (and therefore the cost) will typically reflect the level of activity. Another related notion is Platform as a Service, PaaS which is a delivery model of a computing platform and solution stack as a service. It 


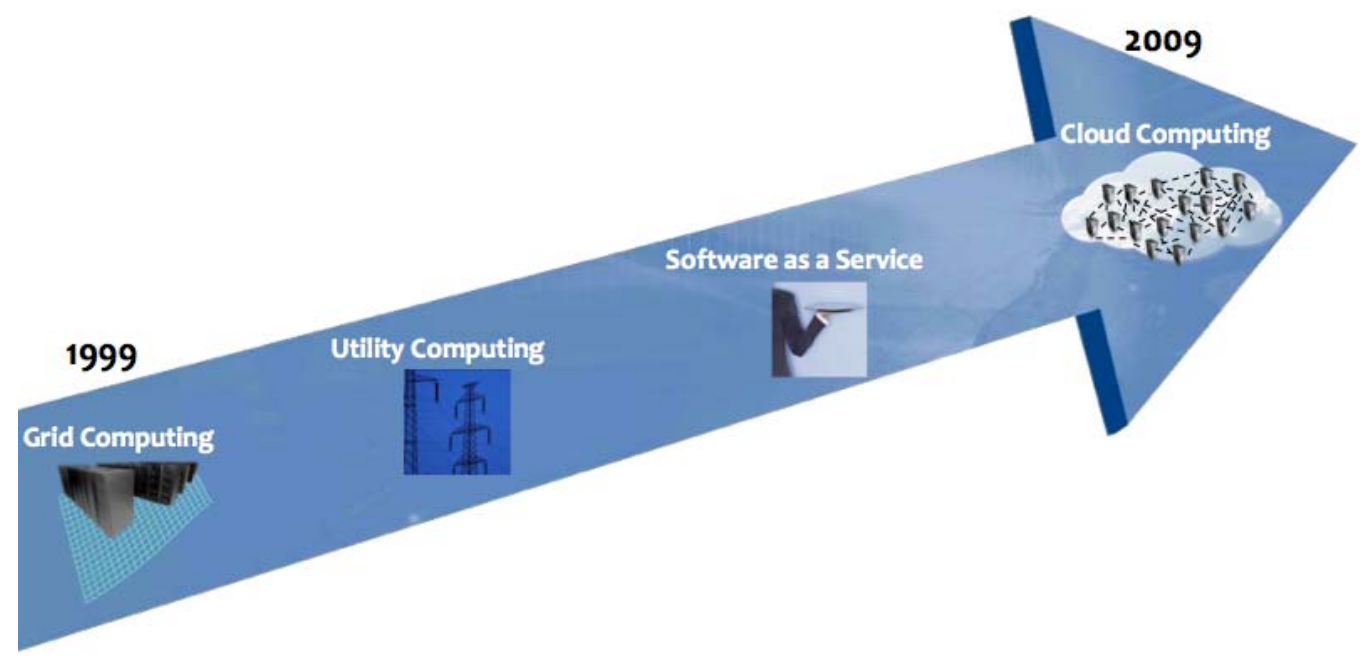

Fig. 1. Evolution of technology leading to Cloud Computing.

facilitates deployment of applications without the cost and complexity of buying and managing the underlying hardware and software, and of provisioning hosting capabilities. Instead, it supports the complete life cycle of applications and services entirely from the Internet.

\section{An IT Delivery View}

Another way to understand the implications of Cloud Computing in the IT industry is to see how IT has been delivered to the customers in its history of past several decades. In old days of the 1970s and 1980s, IT providers were fragmented and each of them sold different parts of an IT solution, i.e., hardware, software and services, separately to the customers. Then it was the customers that assemble and configure a solution they need by putting together various parts purchased from multiple vendors of hardware, software and services. Then the IT market was fragmented with various flavors of hardware, software and services. The ecosystem of IT vendors was centered on the platforms defined mostly by Operating Systems, e.g., Windows, UNIX, and mainframe. Software vendors developed and deployed their applications on the platforms.

Scott McNealy once compared the development of a systems project in the old days to an airplane assembly where the "owner" buys parts from many suppliers, a wheel here, a seat there, a bit of a wing somewhere else.
They then set up their own hanger near a runway and commence assembling this plane. He pointed out that the customer is not interested in the parts; they want a solution, i.e., an airplane for transportation, where the parts are hidden beneath a "blanket". The idea is to outline the solution and assume that the blanket can handle the implementation. [3]

In the 1990s and on, several trends in IT delivery towards realizing the solution-centric vision were seen. Most notably, the era saw the emergence of packaged applications from SAP and other vendors, most of which were later acquired by Oracle. The packaged applications were initially known as ERP (Enterprise Resource Planning) systems. They provide an integrated set of applications running on a common database, and offering a consistent look and feel throughout each module. Therefore, at least, in theory, installation of the systems does not require elaborate application and data integration. In reality, however, packaged application projects tend to quickly grow heavy-weighted and complicated. The installation and configuration of the packages for enterprise customers often become complex, expensive multi-year projects. It started off another trend in the era when several service vendors known as "vertical integrators" such as IBM and Accenture take on large-scaled enterprise IT delivery projects by assembling and configuring solutions for the 
customers with hardware, middleware and applications - packaged or not.

The era saw IT service providers who are capable of putting together cost-effective solutions by vertically integrating hardware, software and services started dominating the business model. Customers could purchase solutions assembled and configured by the service providers. Sometimes, however, the solutions can be inflexible, huge and expensive. The ecosystem of IT vendors in the era was centered on the packaged application platforms, SAP or Oracle, and the service vendors. Software vendors in the era developed and deployed on the packaged application platforms.

The Cloud Computing revolution we see at present offers a new consumption and delivery model for IT services, but is rooted in the industrialization of IT delivery started in the 1990s. Its user experience and business model will provide standardized offerings rapidly provisioned and flexibly priced. Its infrastructure management and services delivery method will provide virtualized resources managed as a single large resource, and deliver services with elastic scaling. Similar to Banking ATMs and Retail Point of Sale, Cloud will be driven by self-service, simplification, standardization, economies of scale, and technology advancement. With Cloud Computing, IT providers standardize solutions and deployed them on the cloud, making them available to the customers as services. They only need to "pay for the fare, but not for the bus or airplane.” They can subscribe to integrated services. In the cloud, services and infrastructure can be shared among the customers, or passengers. In this paradigm, cloud service providers who are capable of providing an ecosystem and a platform by operating the "airline company" will dominate the business model with new markets and opportunities. The ecosystem will be centered on cloud platforms where software vendors and other value-add players will deploy their services. The vendors will reach more "passengers" by adding services to the platforms.

\begin{tabular}{|c|c|c|}
\hline $\begin{array}{l}\text { IT Providers sold parts (software, hardware, } \\
\text { and services) separately to customers. }\end{array}$ & $\begin{array}{l}\text { IT providers assemble \& configure solutions for } \\
\text { customers (a.k.a. vertical integration). For } \\
\text { example, IBM's packaged application service } \\
\text { business (e.g., SAP \& Oracle). }\end{array}$ & $\begin{array}{l}\text { IT providers assemble solutions and deploy } \\
\text { them on the cloud, making them available to } \\
\text { customers as services. }\end{array}$ \\
\hline $\begin{array}{l}\text { Customers purchased parts possibly from } \\
\text { multiple vendors. In-house IT assembled and } \\
\text { configured solutions by using the parts. }\end{array}$ & $\begin{array}{l}\text { Customers purchase assembled \& configured } \\
\text { solutions from service vendors. Sometimes, the } \\
\text { solutions can be huge and very expensive. }\end{array}$ & $\begin{array}{l}\text { Customers "pay for the ticket, but not for the } \\
\text { bus." They can subscribe and integrate } \\
\text { services. The services and infrastructure can } \\
\text { be shared among customers, i.e., tenants. }\end{array}$ \\
\hline $\begin{array}{l}\text { Customers deal with fragmented markets } \\
\text { for hardware, software and services. Each } \\
\text { market further fragmented with various } \\
\text { flavors of hardware, software and services. }\end{array}$ & $\begin{array}{l}\text { Market: IT service providers who are capable of } \\
\text { putting together cost-effective solutions by } \\
\text { vertically integrating hardware, software, and } \\
\text { services dominate this business model. }\end{array}$ & $\begin{array}{l}\text { Cloud providers who are capable of providing } \\
\text { ecosystem and platform by operating the } \\
\text { "bus company" dominate the business model } \\
\text { with new markets \& opportunities. }\end{array}$ \\
\hline $\begin{array}{l}\text { There are ecosystems around platforms } \\
\text { defined mostly by OS (Wintel, UNIX, } \\
\text { mainframe). ISVs deploy their software on } \\
\text { the platforms. }\end{array}$ & $\begin{array}{l}\text { There are ecosystems around platforms defined } \\
\text { by solutions (e.g., SAP, and Oracle). ISVs deploy } \\
\text { their software around the solution platforms. }\end{array}$ & $\begin{array}{l}\text { Ecosystem: Platforms for ISVs deploying } \\
\text { software as a service (e.g., Saleforce.com, and } \\
\text { municipal cloud) are forming. ISVs can reach } \\
\text { "passengers" by adding services to the "bus." }\end{array}$ \\
\hline
\end{tabular}

Fig. 2. Evolution of IT Delivery leading to Cloud Computing. 


\section{A Deployment Model View}

With all the promises of Cloud Computing, it is important to note that we are still in very early stage of the revolution that will last for a while and drastically change the IT delivery in the future. In the beginning, the benefit will be realized in a limited scope where the new model in its present form fits best. It may include pre-production systems where software is designed, implemented and tested by engineers, storage solutions that provide backup and restore solutions, information archival and, perhaps, some data intensive workloads, mature packaged offerings such as collaboration solutions, e.g., email and calendar systems, and batch processing systems with isolated workloads. On the other hand, the benefits of cloud computing may not be immediately realized in some areas including solutions requiring sensitive data such as healthcare record and employment information, high throughput online transaction processing solutions involving multiple codependent services, solutions requiring high auditability and accountability, and solutions requiring third-party software which does not offer virtualization or cloud aware licensing.

It is also important to note that there will be multiple deployment models of cloud co-existing in the future with traditional enterprise IT environment. There will be private cloud and public cloud depending on who are allowed the deployed cloud. In addition, there will be variations such as "community cloud” requiring certain memberships for access. Also, there will "hybrid cloud" which will allow access to solutions across different deployment models. While enterprises will depend on the traditional enterprise IT environment for certain tasks such as mission-critical solutions, packaged applications and high-compliancy applications, they will employ private clouds for pre-production and test system and development platforms, and utilize public clouds for Software-as-a-Service, Web hosting and storage solutions. They will also depend on hybrid clouds to make the solutions working between private and public clouds they utilize.

There may be multiple cloud delivery models offered by cloud service providers. A private cloud service will be owned by an enterprise. It can be either operated/managed by the enterprise, or by a 3rd-party cloud service provider that offers the service for a fixed or variable price. It will be used for an internal network and leverage dedicated resources. A public cloud service will utilize shared resources, and offer elastic scaling and "pay-as-you-go" pricing. It will provide public access to the service. Between the two service models is the shared service that will depend on mix of shared and dedicated resources. It will also share facility and staff with other cloud services. It will employ VPN (Virtual Private Network) access on a public Internet access. Figure 3 shows the IT deployment models related to Cloud Computing.

Multiple Types of Clouds will co-exist:

- Private, Public and Hybrid

- Workload and / or Programming Model Specific

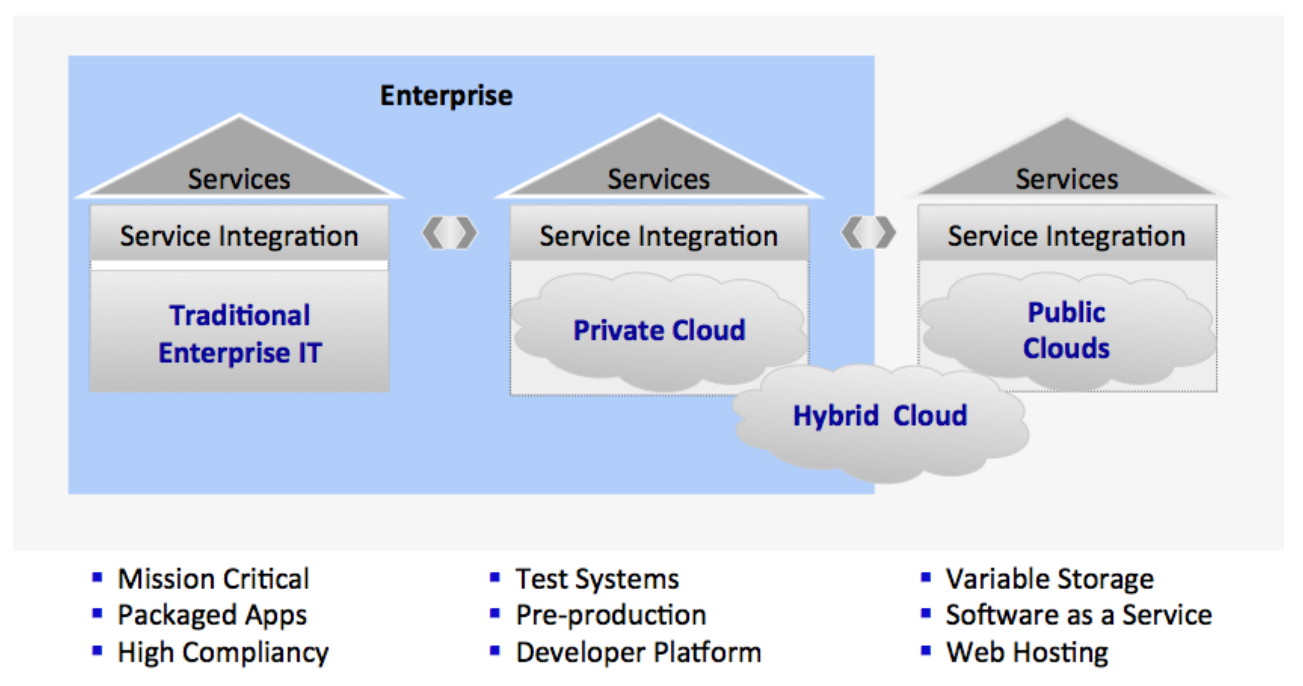

Fig. 3. IT deployment models in the future. 


\section{An Economic View}

With the Cloud economics driven by self-service, simplification, standardization, and economies of scale, enterprise clouds offer significant operational efficiencies through virtualization and image management. Also, cloud service providers with highly standardized workloads drive even further cost optimization for data centers. IT benefits will lie in increased speed and flexibility of IT delivery and reduced cost. As for the speed and flexibility, the time for test provisioning will be reduced to minutes from the current weeks. The effort for change management will be reduced up to days if not hours from the current months. The release management will be sped up to minutes from weeks. The service access will be mostly self-service and minimize the need for administration. The standardization in the process will foster reuse and sharing of resources and control the complexity. The metering and billing capability of cloud computing will enable variable and flexible pricing and removing fixed costing and pricing. The utilization of servers and storage will be increased to $70-90 \%$ from the current $10-20 \%$. Overall, the payback period of the IT infrastructure will be reduced to months from years.

Cloud economics will enable reduction of infrastructure and labor costs. As for the infrastructure cost, virtualization of hardware will drive lower capital requirements and improve the utilization of infrastructure. As for the labor leverage, self-service will reduce the cost for customer support and maintenance. Management automation will remove the need for repeated tasks in administration. Also standardization will minimize the complexity leading a higher level of automation and reduced labor. Figure 4 summarizes the IT benefits of Cloud Computing based on IBM and customer experience.

It is important to note, however, these benefits come with a number of risks and issues including information security and user privacy, service continuity, cost of data migration to cloud, and other political and economic problems. First, using a cloud computing service to store data may expose the user to potential violation of privacy. For example, imagine a scenario where sensitive data of an enterprise and personal data of a user is entrusted to a cloud provider. It is possible to imagine illegal acts like misappropriation of personal data or sensitive data, e.g., corporate espionage or user profiling for marketing, by the provider or hackers. Especially when the cloud provider may reside in a country other than the enterprise's and the user's, there will be more difficult to reach legal solutions. In addition, leaving their data managing and processing to an external service, users of Cloud Computing take the risk of being limited when the service is out. In Cloud Computing, any malfunction of the service will affect a large number of users at once because the service is

\begin{tabular}{|c|c|c|c|}
\hline & from IBM cloud computing & gagements & \\
\hline \multirow{6}{*}{$\begin{array}{l}\text { Increasing } \\
\text { speed and } \\
\text { flexibility }\end{array}$} & Test provisioning & Weeks & Minutes \\
\hline & Change management & Months & Days/hours \\
\hline & Release management & Weeks & Minutes \\
\hline & Service access & Administered & Self-service \\
\hline & Standardization & Complex & Reuse/share \\
\hline & Metering/billing & Fixed cost & Variable cost \\
\hline \multirow{2}{*}{$\begin{array}{r}\text { Reducing } \\
\text { costs }\end{array}$} & Server/storage utilization & $10-20 \%$ & 70-90\% \\
\hline & Payback period & Years & Months \\
\hline
\end{tabular}

Fig. 1. IT benefits of Cloud Computing 
often shared on a large network. Another issue is related with the data migration or porting when a user wants to change the cloud provider. At present, there is no defined standard between the operators and also such a change can be very complex. The case of bankruptcy of the cloud provider company could be risky for the users.

\section{Conclusion}

Cloud computing will transform the information technology industry and profoundly change the way people work and companies operate. [1] It provides a new paradigm for consumption and delivery of IT based services. It also provides an enhanced user experience with a self-service user interface for IT management. It abstracts the technical details from end-users so that they no longer need expertise in, or control over, the technology infrastructure "in the cloud" that supports them. It provides flexible pricing based on pay per usage. It enables flexible delivery and sourcing models including private, public and hybrid clouds. Finally, it provides automated provisioning and elastic scaling of IT infrastructure. We presented in this paper several views on different perspectives of Cloud Computing, including technical advancement, IT delivery and deployment modes, and economics.

\section{References}

References are to be listed in the order cited in the text. Use the style shown in the following examples. For journal names, use the standard abbreviations. Typeset references in 9 pt Times Roman.

1. The Economist, "A survey of corporate IT: Let it rise", October 23, 2008, http://www.economist.com/node/12411882?story_id=124 11882.

2. IBM, "'Virtualization in education", October 2007, http://www07.ibm.com/solutions/in/education/download/Virtualizati on\%20in\%20Education.pdf

1. Scott McNealy, guest speech at a brunch hosted by the Australia-Israel Chamber of Commerce, 2003, http://ozguru.mu.nu/mt3/archives/2003/03/scott_mcnealy .html. 